\title{
PENGARUH APLIKASI MUZAKI CORNER TERHADAP MINAT MASYARAKAT BERZAKAT
}

\author{
Muhammad Kambali ${ }^{\bowtie}$, Fatur Rahman \\ Sekolah Tinggi Agama Islam (STAI) Al-Azhar Menganti Gresik, Indonesia \\ hambali236@gmail.com, alialfarisi75@gmail.com \\ https://doi.org/10.46367/iqtishaduna.v10i2.413 \\ Received: Oct 14, 2021 Revised: Nov 09, 2021 Accepted: Nov 19, 2021 Published: Des 17, 2021
}

\begin{abstract}
This research aims to show the effect of using the muzaki corner application on muzaki interest in tithing. The research method uses a quantitative approach. The population in this study were all muzaki of the Gresik National Amil Zakat Agency, who used the muzaki corner application. The sample in this study was 80 respondents. Data were collected through questionnaires with an accidental sampling technique. Data were analyzed using simple linear regression, hypothesis testing, and coefficient of determination. The results showed that using the muzaki corner application affected people's interest in tithing, with an effect of 92.3\%. In comparison, $7.7 \%$ was influenced by other factors that were not included in this research model. This research can strengthen the growth and development of public interest in tithing at the National Amil Zakat Agency.
\end{abstract}

Keywords: Applications, Muzaki Corner, Interests, Zakat.

\begin{abstract}
ABSTRAK
Penelitian ini bertujuan untuk menunjukkan pengaruh penggunaan aplikasi muzaki corner terhadap minat muzaki dalam berzakat. Metode penelitian menggunakan pendekatan kuantitatif. Populasi dalam penelitian ini adalah seluruh muzaki Badan Amil Zakat Nasional Gresik yang menggunakan aplikasi muzaki corner. Sampel dalam penelitian ini sejumlah 80 orang responden. Data dihimpun melalui kuisioner dengan teknik accidental sampling. Data di analisis dengan menggunakan regresi linier sederhana, uji hipotesis dan koefisien determinasi. Hasil penelitian menunjukkan bahwa penggunaan aplikasi muzaki corner berpengaruh terhadap minat masyarakat dalam berzakat, dengan pengaruh sebesar 92,3\% sedangkan 7,7 \% dipengaruhi oleh faktor lain yang tidak masuk dalam model penelitian ini. Penelitian ini dapat memperkuat tumbuh kembangnya minat masyarakat dalam berzakat pada Badan Amil Zakat Nasional.
\end{abstract}

Kata Kunci: Aplikasi, Muzaki Corner, Minat, Zakat.

\section{PENDAHULUAN}

Zakat merupakan satu kewajiban yang harus ditunaikan oleh umat Islam. Zakat secara bahasa dapat diartikan dengan tumbuh, berkembang dan tambah. Potensial zakat yang dimiliki Indonesia sangatlah besar, hal ini dikaitkan dengan jumlah umat Islam yang merupakan umat mayoritas di Indonesia. Menurut wakil presiden Ma'ruf Amin potensi zakat yang terdapat di Indonesia berkisar 327,6 
Triliun (Safutra 2021). Namun hal tersebut berbanding terbalik dengan besaran realisasi pengumpulan dana zakat yang baru terkumpul sekitar 71,4 Triliun (Safutra 2021). Kondisi tersebut dipengaruhi oleh banyak faktor, salah satunya adalah tata kelola lembaga yang profesional dan akuntabel sehingga melahirkan kepercayaan di masyarakat, sehingga menyalurkan zakatnya secara resmi pada lembaga-lembaga pengumpul zakat (Cahyani, Aviva, and Manilet 2019).

Indonesia sudah melakukan optimalisasi penyerapan dana zakat sesuai regulasi. Salah satu ketentuan tersebut adalah undang-undang nomor 38 tahun 1999 tentang penyelenggaraan zakat. Salah satu poin penting dalam undangundang tersebut adalah pengelolaan zakat harus dikelola oleh badan atau lembaga yang profesional (BAZNAS 2021). Badan Amil Zakat Nasional (BAZNAS) Gresik sebagai bagian dari lembaga pemerintah non struktural di Kabupaten Gresik memiliki tugas menghimpun dan menyalurkan dana zakat, infaq dan sedekah (ZIS) di wilayah Kabupaten Gresik. Sebagai wujud pelaksanaan tugas yang di emban, BAZNAS Gresik senantiasa berusaha melakukan terobosan dalam segala lini kegiatan yang dijalankan. Salah satu adalah pada lini fund rissing yang dalam rangka untuk meningkatkan animo atau minat masyarakat untuk membayar zakat di lembaga resmi yakni BAZNAS, maka optimalisasi kegiatan penghimpunan dana zakat pun dilakukan dengan memanfaatkan perkembangan teknologi saat ini yakni dengan penggunaan aplikasi yang diberi nama aplikasi muzaki corner (BAZNASGRESIK 2021).

Penelitian yang sudah ada mengenai minat atau keinginan muzaki atau masyarakat dalam berzakat dapat dilihat dari beberapa aspek yaitu aspek kualitas pelayanan, religiusitas, dan citra lembaga, sudah pernah diteliti oleh (Yazid 2017). Kemudian aspek sikap, norma subjektif, dan kontrol prilaku yang dirasakan, sudah pernah diteliti oleh (Cahyani, Aviva, and Manilet 2019). Selanjutnya aspek kegunaan, akuntabilitas, dan transparasi, sudah pernah diteliti oleh (Kharisma, and Jayanto 2021). Kemudian aspek ekspektasi kinerja, ekspektasi upaya, kondisi fasilitasi, dan literasi zakat, sudah pernah diteliti oleh (Kasri and Yuniar 2021). Namun dari penelitian tersebut belum ditemukan yang meneliti langsung aspek aplikasi muzaki corner dalam mempengaruhi minat masyarakat berzakat, sehingga hal ini dapat dijadikan sebagai pembeda dengan penelitian yang telah ada.

Widodo, Handayani, and Saifi (2013) menyatakan bahwa sistem informasi manajemen sebagai suatu sistem berbasis komputer yang menjadikan informasi tersebut tersedia bagi pengguna yang memiliki kebutuhan sejenis memiliki andil dalam mempengaruhi prilaku masyarakat. Cahyani, Aviva, and Manilet (2019) menyatakan bahwa cendikiawan muslim, pemerintah dan lembaga zakat memiliki peranan penting untuk mendorong masyarakat dalam membayar zakat di lembaga pengumpul zakat. Berangkat dari hal tersebut, faktor peran lembaga zakat menjadi fokus penelitian ini dengan penggunaan aplikasi yang diberi nama muzaki corner. Oleh sebab itu penelitian ini bertujuan untuk menunjukkan seberapa besar pengaruh aplikasi muzaki corner terhadap minat masyarakat dalam berzakat.

\section{TELAAH LITERATUR}

Zakat merupakan salah satu rukun Islam yang wajib ditunaikan bagi umat Islam yang memiliki harta (Anwar 2018; Safradji 2018). Zakat merupakan hak 
yang wajib dikeluarkan dari harta jika sudah memenuhi syarat yang telah ditetapkan bagi umat Islam (Atabik 2015). Zakat berdasarkan atas kebutuhan dalam memberi bantuan sosial dan kesejahteraan umum demi kepentingan dan kemajuan umat Islam (Owoyemi 2020). Zakat merupakan salah satu solusi alternatif untuk mengurangi kemiskinan (Amalia and Mahalli 2012). Zakat dinilai dari dua dimensi yaitu dimensi vertikal berarti ketaatan kepada Allah SWT dan dimensi horizontal berarti kewajiban terhadap sesama manusia (Saputra 2020). Oleh sebab itu zakat dapat dikatakan wujud nyata dari ibadah seorang muslim kepada Allah sekaligus wujud kepedulian sosial (Ishak 2012). Perintah Allah SWT tentang kewajiban zakat terdapat dalam surat At-Taubah ayat 103:

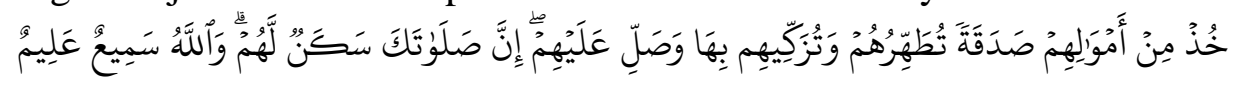

Artinya: "Ambillah zakat dari harta mereka guna membersihkan dan menyucikan mereka dan berdoalah untuk mereka. Sesungguhnya doamu itu (menumbuhkan) ketenteraman jiwa bagi mereka. Allah Maha Mendengar, Maha Mengetahui”.

Semenjak tahun 2012 BAZNAS sudah memiliki sistem zakat online untuk para muzaki (Hendarsyah 2013). Sistem zakat online BAZNAS disebut juga dengan aplikasi muzaki corner, dengan tujuan untuk dapat mempermudah nuzaki agar dapat berzakat di BAZNAS tanpa perlu datang ke kantor BAZNAS. Aplikasi ini dapat digunakan melalui website atau smartphone oleh muzaki yang sudah mendapatkan nomor pokok wajib zakat (NPWZ) (Hendarsyah 2013). NPWZ merupakan nomor identitas bagi muzaki BAZNAS dalam layanan pembayaran zakat, infaq dan sedekah. Cara mendapatkan NPWZ adalah dengan mendaftarkan diri terlebih dahulu di kantor BAZNAS atau bisa melalui email BAZNAS dengan mengisi formulir data diri yang dibutuhkan BAZNAS atau bisa langsung registrasi melalui webite muzaki corner (BAZNAS 2021). Penggunaan teknologi dapat digunakan dalam administrasi pengelolaan zakat, penyediaan layanan zakat online dan pelaporan zakat kepada masyarakat (Mutamimah, Alifah, Gunawan, and Adnjani 2021).

Menurut McLeod and Schell (2008) bahwa faktor yang mempengaruhi penggunaan aplikasi sistem informasi manajemen dapat di identifikasi menjadi beberapa faktor yaitu: kemudahan, kecepatan dan keakuratan data. Sedangkan Widodo, Handayani, and Saifi (2013) menyatakan bahwa faktor-faktor yang mempengaruhi penggunaan aplikasi sistem informasi manajemen dapat diidentifikasi menjadi beberapa faktor yaitu: aksesibilitas, kelengkapan, akurasi, kesesuaian, ketepatan waktu, kejelasan, fleksibilitas, keterverifikasian, tidak ada prasangka (bebas dari bias) dan terukur.

Minat dapat diartikan dengan kecenderungan seseorang atau ketertarikan seseorang pada satu obyek tertentu (Nisa 2015). Minat merupakan salah satu aspek psikologi yang mempunyai pengaruh yang signifikan terhadap tingkah laku dan minat juga merupakan sumber motivasi yang akan mengarahkan seseorang dalam melakukan apa yang mereka lakukan. Dengan demikian dapat di artikan bahwa minat Muzaki adalah kecenderungan yang terdapat dalam diri seseorang untuk mengeluarkan zakat. Minat muzaki bisa diukur dengan beberapa dimensi yaitu: ketertarikan (interest), keinginan (desire), keyakinan (conviction) (Sobana, Husaeni, Jamil, and Saepudin 2016).

Penelitian yang sudah dilakukan oleh Yazid (2017) menyatakan bahwa kualitas pelayanan, religiusitas, dan citra lembaga berpengaruh terhadap minat muzaki dalam menunaikan zakat. Penelitian yang sudah dilakukan oleh Cahyani, 
Aviva, and Manilet (2019) menyatakan bahwa kontrol perilaku yang dirasakan berpengaruh terhadap intensi muzaki dalam membayar zakat. Penelitian yang sudah dilakukan oleh Kharisma, and Jayanto (2021) menyatakan bahwa kegunaan, risiko, dan transparansi berpengaruh terhadap minat dalam menggunakan e-zakat dalam membayar ZIS. Penelitian yang sudah dilakukan oleh Kasri and Yuniar (2021) menyatakan bahwa ekspektasi kinerja, ekspektasi upaya, kondisi fasilitasi, dan literasi zakat berpengaruh signifikan terhadap niat menggunakan platform online untuk membayar zakat. Berdasarkan hasil penelitian tersebut dapat dilihat bahwa variabel bebas dari masing-masing penelitian berpengaruh terhadap minat atau keinginan, niat muzaki membayar zakat. Oleh sebab itu dapat dirumuskan hipotesis penelitian yaitu: $\left(\mathrm{H}_{1}\right)$ : aplikasi muzaki corner berpengaruh signifikan terhadap minat masyarakat berzakat.

\section{METODE PENELITIAN}

Penelitian ini merupakan penelitian lapangan, dengan menggunakan pendekatan kuantitatif. Populasi dalam penelitian ini berjumlah 100 orang. Teknik pengambilan sampel yang digunakan adalah teknik accidental sampling. Teknik ini digunakan dengan mempertimbangkan sebaran populasi yang cukup luas dan waktu yang terbatas, sehingga setiap orang yang ditemui dan sesuai dengan deskripsi sumber data, dijadikan sebagai responden. Sehingga dengan teknik tersebut diperoleh jumlah sampel sebanyak 80 orang. Sumber data penelitian ini adalah data primer menggunakan kuesioner tertutup dengan skala likert. Analisis data yang dilakukan peneliti dimulai dengan telaah instrumen yang terdiri dari uji validitas, uji reliabilitas dan uji normalitas. Setelah itu dilakukan uji regresi linier sederhana, uji t dan koefisien determinasi.

\section{HASIL DAN PEMBAHASAN PENELITIAN}

\section{Data Responden}

Responden dalam penelitian ini adalah muzaki BAZNAS Gresik yang berjumlah 80 orang dengan kriteria muzaki yang menggunakan aplikasi muzaki corner. Responden penelitian ini diperoleh melalui penyebaran kuesioner selama 15 hari penelitian. Data responden dibagi dalam beberapa karaktistik meliputi jenis kelamin, usia, dan tempat tinggal. Berdasarkan jenis kelamin jumlah responden pria sebanyak 32 orang $(40 \%)$ dan wanita sebanyak 48 orang $(60 \%)$. Jenis kelamin yang dominan adalah wanita. Jumlah responden berdasarkan rentang usia 20-30 tahun sebanyak 20 orang (25\%), rentang usia 31-40 tahun sebanyak 39 orang (48,75\%), rentang usia > 40 tahun sebanyak 21 orang $(26,25 \%)$. Rentang usia yang dominan adalah usia 31 sampai 30 tahun. Sedangkan responden berdasarkan tempat tinggal dapat dilihat pada Tabel 1. Berdasarkan Tabel 1 dapat dilihat bahwa persentase tertinggi pengguna aplikasi muzaki corner bertempat tinggal di kecamatan Kebomas sebanyak 21 orang (26,25\%). Sedangkan persentase terendah pengguna aplikasi muzaki corner terdapat di beberapa kecamatan Balongpanggang, Driyorejo, Sangkapura, Sidayu dan Wringinanom, masing-masing sebanyak 1 orang $(1,25 \%)$. 
Tabel 1. Responden Berdasarkan Tempat Tinggal

\begin{tabular}{clcc}
\hline No & Tempat Tinggal & Jumlah & Prosentase \\
\hline 1 & Balongpanggang & 1 & $1,25 \%$ \\
2 & Benjeng & 4 & $5 \%$ \\
3 & Bungah & 6 & $7,5 \%$ \\
4 & Cerme & 4 & $5 \%$ \\
5 & Driyorejo & 1 & $1,25 \%$ \\
6 & Duduk Sampeyan & 4 & $5 \%$ \\
7 & Dukun & 2 & $2,50 \%$ \\
8 & Gresik & 20 & $25 \%$ \\
9 & Kebomas & 21 & $26,25 \%$ \\
10 & Manyar & 12 & $15 \%$ \\
11 & Paanceng & 1 & $1,25 \%$ \\
12 & Sangkapura & 2 & $2,50 \%$ \\
13 & Sidayu & 1 & $1,25 \%$ \\
14 & Wringinanom & 1 & $1,25 \%$ \\
\hline \multicolumn{2}{r}{ Total } & $\mathbf{8 0}$ & $\mathbf{1 0 0 \%}$ \\
\hline
\end{tabular}

Sumber: data primer (diolah)

\section{Uji Validitas}

Validitas merupakan ukuran yang menunjukkan tingkat ketelitian instrumen terhadap suatu konsep yang diteliti. Untuk mengukur validitasnya, parameter yang digunakan adalah nilai korelasi yang positif dan tingkat alpha $5 \%$. Adapun kreteria yang dipakai dalam menentukan validitas adah jika nilai $r_{\text {hitung }}>$ $\mathrm{r}_{\text {tabel }}$, maka dinyatakan valid, sebaliknya jika $\mathrm{r}_{\text {hitung }}<\mathrm{r}_{\text {tabel }}$ maka instrumen dinyatakan tidak valid. Diketahui $\mathrm{n}=80 ; \alpha=0,05 ; \mathrm{df}=\mathrm{n}-2=80-2 ; \mathrm{r}_{\text {tabel }}=0,220$. Hasil uji validitas menunjukkan bahwa variabel aplikasi muzaki corner memiliki nilai $r_{\text {hitung }}$ terendah sebesar 0,827 dan $r_{\text {hitung }}$ tertinggi sebesar 0,909 , berarti $r_{\text {hitung }}>$ $\mathrm{r}_{\text {tabel}}$, sehingga dapat dikatakan bahwa data untuk variabel aplikasi muzaki corner valid. Kemudian variabel minat masyarakat memiliki nilai $r_{\text {hitung }}$ terendah sebesar 0,854 dan $r_{\text {hitung }}$ tertinggi sebesar 0,910 , berarti $r_{\text {hitung }}>r_{\text {tabel }}$, sehingga dapat dikatakan bahwa data untuk variabel minat masyarakat valid.

\section{Uji Reliabilitas}

Suatu variabel dikatakan reliabel (handal) jika memiliki nilai cronchbach alpha > 0,60. Hasil uji reliabilitas menunjukkan bahwa nilai cronchbach alpha untuk variabel aplikasi muzaki corner sebesar 0,789 dan nilai cronchbach alpha untuk variabel minat masyarakat sebesar 0,790. Dari hasil uji reliabilitas nilai cronchbach alpha kedua variabel >0,60, sehingga dapat dikatakan bahwa data reliabel.

\section{Uji Normalitas}

Tujuan dari uji normalitas adalah untuk menentukan apakah variabel berdistribusi normal atau tidak. Uji statistik yang digunakan untuk uji normalitas data dalam penelitian ini dilakukan dengan cara uji KolmogorovSmirnov. Hasil analisis ini kemudian dibandingkan dengan nilai kritisnya. Uji normalitas memiliki kriteria pengambilan keputusan, apabila tingkat signifikansi $>0,05$ maka data berdistribusi normal, sebaliknya tidak normal. Kemudian dari 
grafik normal P-P Plot, jika titik tersebar mengikuti garis diagonal maka data berdistribusi normal, sebaliknya tidak normal.

\section{Gambar 1. Normal P-P Plot}

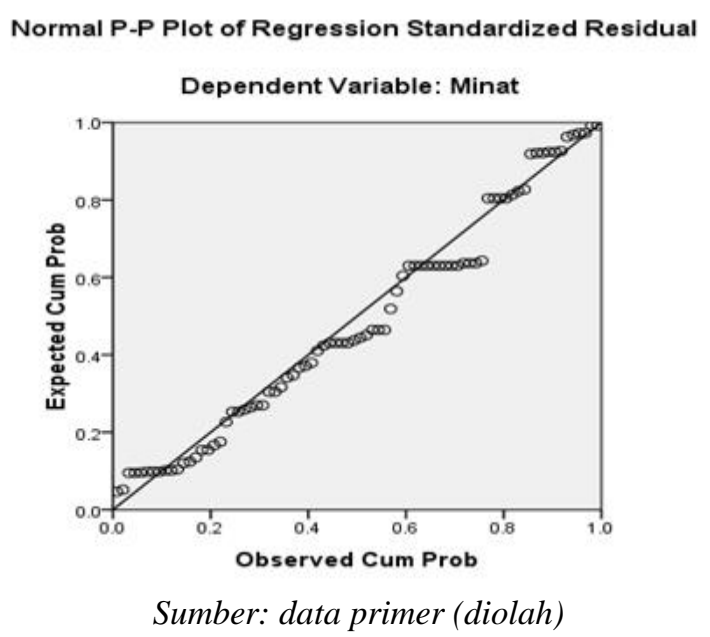

Berdasarkan hasil uji normalitas Kolmogorov-Smirnov didapat nilai signifikansi sebesar 0,210, berarti nilai signifikansi > 0,05. Kemudian berdasarkan grafik normal P-P Plot pada Gambar 1 menunjukkan bahwa titik tersebar mengikuti garis diagonal. Sehingga dari kedua pengujian tersebut dapat dikatakan bahwa data berdistribusi normal.

\section{Regresi Linier Sederhana}

Analisis regresi linier sederhana digunakan untuk memprediksi hubungan variabel bebas terhadap variabel terikat. Model regresi linier yang baik seharusnya melalui beberapa pemeriksaan agar didapatkan model regresi yang tepat, sehingga dapat digunakan untuk menarik kesimpulan. Uji ini bertujuan untuk menunjukkan hubungan matematis antara variabel respon dengan variabel penjelas. Sedangkan, rumus analisis regresi liner sederhana sebagai berikut: $\mathrm{Y}=\alpha+\beta \mathrm{X} ; \mathrm{Y}=$ variabel terikat; $X=$ variabel bebas; $\alpha=$ konstanta; $\beta=$ koefisien regresi.

Tabel 2. Coefficients

\begin{tabular}{lccc}
\hline \multicolumn{1}{c}{ Model } & $\boldsymbol{\alpha} / \boldsymbol{\beta}$ & $\boldsymbol{t}$ & Sig. \\
\hline (Constant) & $-2,000$ & $-1,567$ & 0,121 \\
Aplikasi Muzaki Corner & 1,034 & 30,563 & 0,000 \\
\hline Sumber: data primer (diolah) & & &
\end{tabular}

Berdasarkan Tabel 2 diketahui bahwa koefisien regresi untuk variabel aplikasi muzaki corner adalah 1,034 dan konstanta sebesar -2,000 sehingga model persamaan regresi yang diperoleh adalah: $\mathrm{Y}=(-2,000)+1,034 \mathrm{X}$. Nilai konstanta sebesar -2,000, angka ini memiliki arti bahwa jika tidak ada aplikasi muzaki corner maka nilai minat muzaki berzakat sebesar -2,000. Nilai koefisien regrasi sebesar 1,034, angka ini mengandung arti bahwa setiap penambahan penggunaan aplikasi muzaki corner, maka minat muzaki berzakat akan meningkat sebesar 1,034 . 


\section{Uji T (Parsial)}

Uji t dilakukan untuk mengetahui apakah aplikasi muzaki corner secara parsial berpengaruh signifikan terhadap minat masyarakat berzakat. Ketentuan dalam uji t yaitu tingkat signifikansi $(\alpha)$ sebesar $5 \%$ atau 0,05 . Kemudian ditentukan $\mathrm{t}_{\text {tabel }}$ dengan rumus sebagai berikut: $\mathrm{t}_{\text {table }}=\left(\frac{\alpha}{2}: \mathrm{n}-\mathrm{k}-1\right) ; \mathrm{n}=$ jumlah responden; $\mathrm{k}=$ jumlah variabel bebas; Sehingga, apabila dimasukkan nilainya pada rumus $t$ tabel adalah sebagai berikut: $t_{\text {table }}=\left(\frac{\alpha}{2}: n-k-1\right)=\left(\frac{0,05}{2}: 80-1-1\right)=$ $(0,025: 78)$; Maka, dengan pengujian 2 sisi diperoleh angka $(0,025: 78)$ dapat dicari pada tabel distribusi $\mathrm{T}$ sehingga diperoleh nilai untuk $\mathrm{t}_{\text {tabel }}$ sebesar 1,991. Kriteria pengujian, apabila $t_{\text {hitung }}>t_{\text {tabel }}$ atau nilai Sig. $<0,05$ maka hipotesis diterima, sebaliknya hipotesis ditolak.

Berdasarkan Tabel 2 dapat dilakukan pembandingan $t_{\text {hitung }}$ dengan $t_{\text {tabel }}$ serta nilai Sig. untuk mengetahui pengaruh variabel bebas terhadap variabel terikat secara parsial. Aplikasi muzaki corner memiliki nilai $t_{\text {hitung }}$ sebesar 30,563 dan nilai Sig. sebesar 0,000. Sehingga nilai $t_{\text {hitung }}>t_{\text {tabel }}$ yaitu 30,563 $>1,991$ dan nilai Sig. yaitu $0,000<0,05$ maka hipotesis $\mathrm{H}_{1}$ diterima, artinya bahwa secara parsial terdapat pengaruh yang signifikan antara aplikasi muzaki corner dengan minat masyarakat berzakat.

\section{Uji Koefisien Determinasi}

Analisis determinasi digunakan untuk mengetahui persentase pengaruh variabel besas secara serentak terhadap variabel terikat. Nilai $\mathrm{R}$ berkisar antara 0 1 , nilai semakin mendekati 1 berarti hubungan antara variabel bebas dengan variabel terikat semakin kuat. Sebaliknya, nilai semakin mendekati 0, maka hubungan antara variabel bebas dengan variabel terikat semakin lemah.

Tabel 3. Model Summary

\begin{tabular}{ccc}
\hline $\boldsymbol{R}$ & $\boldsymbol{R}$ Square & Adjusted $\boldsymbol{R}$ Square \\
\hline 0,961 & 0,923 & 0,922 \\
\hline \multicolumn{2}{l}{ Sumber: data primer (diolah) }
\end{tabular}

Berdasarkan Tabel 3 diperoleh nilai $R$ sebesar 0,961 dan mendekati angka 1 , berarti hubungan aplikasi muzaki corner dengan minat masyarakat berzakat sangat kuat. Kemudian nilai $R$ square sebesar 0,923. Nilai ini mengandung arti bahwa pengaruh penggunaan aplikasi muzaki corner terhadap minat masyarakat berzakat di BAZNAS Gresik adalah sebesar $92.3 \%$ sedangkan $7.7 \%$ minat Muzaki berzakat di BAZNAS Gresik dipengaruhi oleh variabel lain yang tidak diteliti dalam penelitian ini.

\section{Pengaruh Aplikasi Muzaki Corner Terhadap Minat Masyarakat Berzakat}

Berdasarkan hasil uji hipotesis diperoleh hasil bahwa Hipotesis $\mathrm{H}_{1}$ diterima, artinya aplikasi muzaki corner berpengaruh signifikan terhadap minat masyarakat dalam berzakat di Baznas Gresik. Kemudian pada Tabel 2 menunjukkan nilai koefisien regresi bernilai positif, artinya aplikasi muzaki corner berpengaruh positif dan signifikan terhadap minat masyarakat dalam berzakat di BAZNAS Gresik. Hal ini mengindikasikan bahwa setiap ada perbaikan atau penyempurnaan pada aplikasi muzaki corner, maka akan 
berdampak pada peningkatan minat masyarakat dalam berzakat di BAZNAS Gresik. Semakin baik aplikasi muzaki corner, maka semakin meningkat minat masyarakat dalam berzakat di BAZNAS Gresik.

Hasil penelitian ini sejalan dengan penelitian yang telah dilakukan oleh Yazid (2017); Cahyani, Aviva, and Manilet (2019); Kharisma, and Jayanto (2021); Kasri and Yuniar (2021) yang menyatakan bahwa variabel bebas dari masing-masing penelitian berpengaruh terhadap minat, keinginan, niat masyarakat dalam membayar zakat. Kemudian hasil penelitian ini juga sejalan dengan penelitian yang dilakukan oleh Mutamimah, Alifah, Gunawan, and Adnjani (2021) yang menyatakan bahwa penggunaan teknologi informasi dapat meningkatkan efisiensi dan efektivitas pengelolaan zakat sehingga dapat meningkatkan pemerataan dan kapasitas dalam penyaluran dan pemberdayaan zakat, dan akhirnya dapat meningkatkan pengentasan kemiskinan.

Berdasarkan hasil penelitian ini, yang perlu dilakukan selanjutnya adalah meningkatkan peran lembaga zakat dalam mempengaruhi prilaku masyarakat muslim supaya mau menyalurkan zakatnya pada lembaga zakat resmi yang ada. Tentu jika hal ini dilakukan maka sebagaimana dipahami bahwa potensi zakat yang tinggi dan rendahnya realisasi zakat, bisa sedikit demi sedikit menjadi berkurang, dengan adanya berbagai macam terobosan yang dilakukan oleh Lembaga Amil Zakat (LAZ) atau BAZNAS. Dengan demikian realisasi penerimaan dana zakat akan semakin mendekati angka potensialnya.

\section{KESIMPULAN}

Aplikasi muzaki corner berpengaruh positif dan signifikan terhadap minat masyarakat dalam berzakat di BAZNAS Gresik. Besar pengaruh aplikasi muzaki corner terhadap minat masyarakat dalam berzakat adalah 92.3\%. Semakin baik fitur yang diberikan dalam aplikasi muzaki corner, maka semakin meningkat minat masyarakat dalam berzakat di BAZNAS Gresik.

Hasil penelitian ini memiliki implikasi dalam rangka memperkuat tumbuh kembangnya minat masyarakat dalam berzakat pada lembaga resmi baik Lembaga Amil Zakat (LAZ) atau BAZNAS. Adapun keterbatasan dalam penelitian ini adalah jumlah variabel bebas penelitian. Kemudian, model sampling yang digunakan adalah accidental sampling, disebabkan sebaran populasi yang cukup luas dan waktu yang terbatas.

Oleh sebab itu perlu dilakukan penelitian lanjutan dengan menambahkan faktor atau variabel lain yang mempengaruhi minat masyarakat karena masih ada ruang sebesar 7,7\%. Kemudian penelitian lanjutan perlu memperbesar jumlah sampel dengan menggunakan probability sampling atau teknik sampel yang lain. Selanjutnya juga perlu melakukan perbandingan dengan kabupaten yang lain selain kabupaten Gresik.

\section{DAFTAR PUSTAKA}

Amalia, Amalia and Kasyfhul Mahalli. 2012. "Potensi dan Peranan Zakat di Kota Medan”. Ekonomi dan Keuangan, 1 (1): 70-87. https://jurnal.usu.ac.id/index.php/edk/article/view/635. 
Anwar, Ahmad Thoharul. 2018. "Zakat Produktif Untuk Pemberdayaan Ekonomi Umat." ZISWAF: Jurnal Zakat Dan Wakaf 5 (1): 41-62. https://doi.org/10.21043/ziswaf.v5i1.3508.

Atabik, Ahmad. 2015. "Manajemen Pengelolaan Zakat Yang Efektif Di Era Kontemporer." Ziswaf: Jurnal Zakat Dan Wakaf 2 (1): 40-62. https://journal.iainkudus.ac.id/index.php/Ziswaf/article/view/1535.

BAZNAS. 2021. "Muzaki Corner.”. https://muzaki.baznas.go.id/.

BAZNASGRESIK. 2021. "Profil Baznas Gresik." https://baznasgresik.com/tentang-kami/sejarah/.

Cahyani, Utari Evy, Itsla Yunisva Aviva, and Aisa Manilet. 2019. "Faktor-Faktor Yang Memengaruhi Intensi Muzaki Dalam Membayar Zakat Di Lembaga." Tazkir : Jurnal Penelitian Ilmu-Ilmu Sosial Dan Keislaman 5 (1): 39-58. https://doi.org/10.24952/tazkir.v5i1.1331.

Hendarsyah, Decky. 2013. "Pemanfaatan Zakat Online Baznas Bagi Muzaki." IQTISHADUNA: Jurnal Ilmiah Ekonomi Kita 2 (2): 485-512. https://doi.org/10.46367/iqtishaduna.v2i2.32.

Ishak, Khodijah. 2012. "Zakat Dalam Sistem Ekonomi Islam Sebuah Alternatif Dalam Peningkatan Kesejahteraan." IQTISHADUNA: Jurnal Ilmiah $\begin{array}{llll}\text { Ekonomi Kita } & 1 & \text { (1): }\end{array}$ http://ejournal.stiesyariahbengkalis.ac.id/index.php/iqtishaduna/article/vie w/10.

Kasri, Rahmatina Awaliah, and Adela Miranti Yuniar. 2021. "Determinants of Digital Zakat Payments: Lessons from Indonesian Experience." Journal of Islamic Accounting and Business Research 12(3): 362-79. https://www.emerald.com/insight/content/doi/10.1108/JIABR-08-20200258/full/html.

Kharisma, Puguh, and Prabowo Yudo Jayanto. 2021. "Faktor-Faktor Yang Mempengaruhi Minat Menggunakan E-Zakat Dalam Membayar Zakat, Infaq, Dan Sedekah.” AKSES: Jurnal Ekonomi dan Bisnis 16(1): 47-56. http://dx.doi.org/10.31942/akses.v16i1.4471.

McLeod, Raymond and George P. Schell. 2008. Sistem Informasi Manajemen. Jakarta: Salemba Empat.

Mutamimah, Mutamimah, Suryani Alifah, Gunawan Gunawan, and Made Dwi Adnjani. 2021. "ICT-Based Collaborative Framework for Improving the Performance of Zakat Management Organisations in Indonesia." Journal of Islamic Accounting and Business Research 12(6): 887-903. https://www.emerald.com/insight/content/doi/10.1108/JIABR-05-20200154/full/html.

Nisa, Afiatin. 2015. "Pengaruh Perhatian Orang Tua Dan Minat Belajar Siswa Terhadap Prestasi Belajar Ilmu Pengetahuan Sosial.” Faktor: Jurnal $\begin{array}{llll}\text { Ilmiah } & \text { Kependidikan } & 2 & \text { (1): }\end{array}$

https://journal.lppmunindra.ac.id/index.php/Faktor/article/view/370.

Owoyemi, Musa Yusuf. 2020. "Zakat Management: The Crisis of Confidence in Zakat Agencies and the Legality of Giving Zakat Directly to the Poor." Journal of Islamic Accounting and Business Research 11 (2): 498-510. https://doi.org/10.1108/JIABR-07-2017-0097. 
Safradji, Safradji. 2018. "Zakat Konsumtif Dan Zakat Produktif." Tafhim Al'Ilmi: Jurnal Pendidikan Dan Pemikiran Islam 10 (1): 59-66. https://doi.org/10.37459/tafhim.v10i1.3246.

Safutra, Ilham. 2021. "Potensi Dana Zakat Rp 327,6 T, Realisasi Baru Rp 71,4 T." https://www.jawapos.com/nasional/06/04/2021/potensi-dana-zakat-rp3276-t-realisasi-baru-rp-714-t/.

Saputra, Hijrah. 2020. "Zakat Sebagai Sarana Bantuan Bagi Masyarakat Berdampak Covid-19.” Al-Ijtima'i: International Journal of Government and Social Science 5 (2): 161-75. https://doi.org/10.22373/jai.v5i2.549.

Sobana, Dadang Husen, Uus Ahmad Husaeni, Irpan Jamil, and Dadang Saepudin. 2016. "The Variables that Affect Compliance of Muslim Merchants for Zakat Maal in the District of Cianjur". International Journal of Zakat, 1 (1): 78-87. https://doi.org/10.37706/ijaz.v1i1.8.

Widodo, Tri Wahyu, Siti Ragil Handayani, and Muhammad Saifi. 2013. "Pengaruh Aplikasi Sistem Informasi Manajemen (SIM) Terhadap Kinerja Karyawan (Studi Kasus Pada Usaha Kecil Menengah Bidang Usaha Warnet Di Kota Malang).” PROFIT: Jurnal Administrasi Bisnis 7 (1): 87100. https://profit.ub.ac.id/index.php/profit/article/view/308.

Yazid, Azy Athoillah. 2017. "Faktor-Faktor Yang Mempengaruhi Minat Muzaki Dalam Menunaikan Zakat Di Nurul Hayat Cabang Jember." Jurnal Ekonomi dan Hukum Islam 8 (2): 173-198. http://ejournal.kopertais4.or.id/tapalkuda/index.php/economic/article/view/ 2991. 